\title{
A Antiguidade, um Erro Profundo?- Foucault, a Filosofia e suas Atitudes
}

[Antiquity, a Deep Error? - Foucault, Philosophy and its Attitudes]

$$
\text { Jean Dyêgo Gomes Soares }
$$

Resumo: Esse artigo visa compreender a afirmação de Michel Foucault de que a Antiguidade seria "um erro profundo". Quando ele fala de suas relações com a filosofia, ele se desloca da pretensão ontológica tradicional para uma prática: ao invés de se perguntar "o que" seriam o poder e a filosofia, ele busca compreender "como" funcionam. Diante desse deslocamento teórico em torno das chamadas "problematizações”, esboça-se uma problematização específica, a do sujeito. Ao destacar descontinuidades desde a Antiguidade até a Modernidade entre estilísticas de si e teorias do sujeito, Foucault permite vislumbrar uma resposta à questão do título. O expediente seria pensar a Antiguidade como um erro profundo, sem, com isso, desconsiderar a atitude também errática do homem moderno.

Palavras-chave: Problematização, Sujeito, Atitude, Modernidade, Baudelaire.

\begin{abstract}
This paper aims to comprehend Michel Foucault's statement that Antiquity would be "a deep error". When he talks on power or its relations with philosophy, he displaces himself from a traditional and ontological pretension to a practical one: instead of asking "what" would be power and philosophy, he seeks to comprehend "how" they work. Having in mind this theoretical displacement on "problematizations", we take as an example that on the subject. Foucault shows discontinuities soughed up for him since Antiquity to Modernity, detailing differences between stylistics of self and theories of the subject. In such a way, we found and answer to the title question. The strategy is to think Antiquity as an error, as well as considering the erratic attitudes of the modern humankind.
\end{abstract}

Keywords: Problematization, Attitude, Subject, Modernity, Baudelaire.

Michel Foucault dedicou parte relevante de sua vida à Antiguidade. Por maiores que sejam as críticas a suas posições teóricas ou a suas leituras, seus trabalhos consti- tuem uma referência estimulante sobre a estética da existência e o cuidado de si. E, no entanto, em sua última entrevista, lemos o seguinte juízo: "Toda a Antiguidade

\footnotetext{
${ }^{*}$ Professor do Centro Universitário Unihorizontes. Doutor em filosofia pela Pontifícia Universidade Católica do Rio de Janeiro (PUC-RJ). E-mail: jeandyego@gmail.com. ORCID: https://orcid.org/0000-0003-1096-9686.
} 
me parece ter sido um 'erro profundo"'. Como entender algo tão assertivo, decidido e direto? Seria contraditório estudar um determinado período considerandoo um "erro profundo"? Devemos ignorar ou relativizar o que está dito, ou devemos tomá-lo a sério.

$\mathrm{O}$ enunciado em questão surge para nós hoje em meio a um conjunto de textos que recobrem trabalhos do autor francês desde 1954 até póstumos publicados em 1988. Os Dits E Écrits (FOUCAULT, 1994), de fato, existe à revelia das recomendações testamentárias de seu autor. Sem nos determos sobre a questão editorial, pois também é verdade que o agora publicado em conjunto fora antes publicado ou aprovado separadamente, é preciso dizer que optamos por trabalhar nossa questão a partir de uma obra incompleta e não aprovada por seu autor, que se estabelece pelo seu fôlego "espontâneo", em formatos diversos, como uma espécie de ensaios de um montaigne no século XX, se o leitor me permite a expressão. Ali, reunidos eles proporcionam uma dimensão única das relações possíveis entre as partes reunidas. Assumindo tal perspectiva, buscaremos compreender essa afirmação aparentemente radical em correlação com outros enunciados que talvez ajudem a sustentá-la. Ao menos em um sen- tido, a analogia procede: ambos fazem convergir um pensamento inquieto em constante retomada com a forma de vida em que se encontram (NEHAMAS, 1998), e isso bastaria para dar atenção à questão que Michel Foucault fez despertar em nós.

Contra ou a favor? Em maio de 1981, Foucault concede uma entrevista a Didier Eribon, seu futuro biógrafo, em que reitera uma posição. Ali, ele sugere uma notável atitude diante de "um governo", ainda que aparentemente favorável, ele não só se dirigia àquele que acabava de ser eleito, François Mitterand, mas se referia a um tema que à época lhe era bastante caro:

É preciso sair do dilema: ou se é a favor, ou contra. Depois de tudo, podese estar de pé e olhando adiante. Trabalhar com um governo não implica nem sujeição, nem aceitação global. É possível às vezes trabalhar e ser rebelde. Acho mesmo que as duas coisas vão juntas (Foucault, 1994-IV, p. $180)$.

A configuração do dilema é clara. Se considerarmos haver um conflito contínuo em curso, ser a fa- 
vor ou contra de maneira irrefletida ajuda pouco a sair do dilema. Isso porque suporíamos posições tão rigidamente encerradas que ou se seria completamente a favor ou completamente contra, ignorando uma infinita gradação de posições entre os extremos. A dignidade de olhar adiante passa por manter uma atitude emancipada, que sabe simultaneamente trabalhar $e$ ser rebelde diante de um governo. Trata-se de não se sujeitar, de não agir contra si mesmo, tampouco assumir uma posição de aceitação mouca e global. Foucault se propõe a tarefa de confrontar o presente, isso implica em, ao experimentá-lo, aprender a tomar posições, discutir, dialogar sobre o que nos tornamos e seremos. Nessa medida, poderíamos ceder a uma sugestão tentadora: a de que ele agiria como o explorador que vai até uma colônia penal. Ali, ele observaria os procedimentos do aparelho, ou em termos foucaultianos, o funcionamento do dispositivo, tiraria suas conclusões e esperaria que a simples discordância performativamente bem cuidada diante do oficial fosse suficiente para pôr termo a uma situação injusta.

Em 1984, em conversa com Alessandro Fontana, ele rechaça essa posição, numa clara resposta a essa crítica. Ali, explicita a ambiguidade dos saberes relaciona- dos ao corpo, ciente de que aqueles sobre os quais ele havia se debruçado ao longo de sua trajetória apresentaram mudanças que "tinham sido profundamente benéficas". Fontana emenda: "Então, esses saberes nos ajudam a viver melhor..." e ele esclarece:

Não houve uma simples mudança nas preocupações, mas no discurso filosófico, teórico e crítico: com efeito, na maior parte das análises feitas, não se sugere às pessoas o que elas deveriam ser, o que deveriam fazer, o que deveriam crer ou pensar. Trata-se mais de fazer aparecer como até o presente os mecanismos sociais teriam se colocado em jogo, como as formas de repressão e de coerção teriam agido, e assim, a partir daí me parece que se daria às pessoas a possibilidade de se determinar, de fazer, ciente de tudo isso, a escolha de sua existência (Foucault, 1994-IV, p. 732).

Foucault não sugere como jogar o jogo, ou seja, não manifesta preocupações normativas, e vê isso como uma mudança no discurso 
filosófico. Como no caso de um texto de jornal de Kant (2012; Foucault 1978, 2010), trata-se menos de dizer como o outro deve ou não agir, e mais de sugerir que ele pode agir diferentemente, que pode ousar saber. Em uma formulação simples, não se trata de ensinar como o jogo da verdade deve ser jogado, mas de analisar como ele vem sendo jogado para permitir que cada um avance por si mesmo nas jogadas. Ao fazer isso, todavia, Foucault não assume uma posição de observador exterior, cujo objetivo seria o de sempre se posicionar "fora daqui", quixotescamente sem quaisquer provisões e disposto a morrer de fome se as condições forem adversas. Ele faz suas análises para permitir que cada um escolha os conflitos, os jogos que deseja enfrentar. Com isso, ele não deseja encontrar um lugar de plena autonomia individual, mas sim permitir que cada um faça as escolhas de sua existência, um processo complexo que depende simultaneamente do desenvolvimento de capacidades biológicas e sociais, capaz de permitir que "os indivíduos determinem a si mesmos" sem que isso exija uma recusa da liberdade social, muito pelo contrário, permitindo simultaneamente esse exercício por parte de todos.

Judith Butler fornece uma com- paração bastante elucidativa sobre as relações entre o poder e os sujeitos. Para ela, acostumamo-nos a pensar no poder como algo que pressiona o sujeito exteriormente, subordinando e relegando-o a ordens inferiores, o que seria uma descrição justa, mas parcial do que faz o poder. A autora, no entanto, adverte: "se entendemos o poder também como algo que forma o sujeito, que determina a própria condição de sua existência e a trajetória de seu desejo, o poder não é apenas aquilo a que nos opomos, mas também, e de modo bem marcado, aquilo de que dependemos para existir e que abrigamos e preservamos nos seres que somos" (Butler, 2017, p. 9). Em outros termos, ela sugere que esses processos não só perpetuam o jogo tal como foi jogado, e contra o qual se opõe, como também se o situarmos enquanto problema, isso assim o será porque o que somos está ligado a ele. Através deste problema, compreendemos como nos tornamos o que somos.

No início do verbete sobre si mesmo, Foucault fornece duas definições negativas de sua história crítica do pensamento, elucidativas nesse ponto, a saber: ela não constitui uma "história das ideias que seria ao mesmo tempo uma análise dos erros que se poderia retrospectivamente mensurar;" tampouco "uma decifração 
dos desconhecimentos pelos quais elas estavam ligadas e das quais o que pensamos hoje poderia depender" (Foucault, 1994-IV, p. 631). Essa definição desvia a posição de Foucault de uma história das soluções, que desejasse responder a problemas atuais com respostas de um ontem. É preciso considerar que para aceitar soluções de outrora para o agora, pressuporríamos uma medida ahistórica para o que é certo e errado; e a posição de Foucault em seu retorno à antiguidade não é a de decifrar algo que está escondido, que supõe agora mostrar, para solucionar um problema atual.

As duas definições negativas fornecidas colaboram para perceber como Foucault pretende não ceder à lógica do "contra ou a favor". Ao propor uma história crítica, ele não cede à vontade de normalizar a história a partir de critérios ahistóricos - não denega o presente em nome de uma nostalgia do passado; tampouco desenvolve uma necessidade incessante de tornar obsoleto o que passou a partir da hegemonia dos critérios do presente. Nota-se que ele não se arroga a pretensão de falar de algo que ninguém falou, de decifrar o desconhecido, passando ao largo de preocupações com o desvelamento de totalidades escondidas, de sentidos profundamente encobertos, e de verdades últimas e universais não-reveladas.

Antes de passarmos à definição positiva, é notável o sintagma sugerido por ele para definir seu trabalho de pesquisa, a saber, história crítica do pensamento. Notável porque uma "história crítica" por si só chama a atenção: remete simultaneamente ao legado kantiano da crítica, enquanto crítica da razão, de seus limites, de suas condições de possibilidade transcendentais; e remete também ao trabalho de um historiador que nega a necessidade de transcendentalidade para se inspirar em um estilo bastante nietzschiano de fazer a história, a ponto de aceitar a sugestão de que o que fazia, no fundo, era uma "nova genealogia da moral" (Foucault, 1994-IV, p. 731). Então não seria a "história crítica do pensamento" um sintagma para a filosofia de Foucault? Ou ao menos para sua "história da filosofia"?

A definição positiva é fornecida algumas linhas depois, a saber, "uma história crítica do pensamento seria uma análise das condições pelas quais são formadas e modificadas certas relações entre sujeito e objeto, na medida em que ambos são constitutivos de um saber possível" (Foucault, 1994-IV, p. 632). Aqui, esbarramos em um deslocamento importante. Menos do que saber o que é o sujeito ou o objeto, questões características 
da história tradicional da filosofia, Foucault fala de condições de formação e modificação, em termos semelhantes às condições de possibilidade da crítica kantiana. Porém, nota-se um tom genealógico inconfundível, uma vez que essas condições parecem remeter às enfatizadas condições de proveniência e emergência de que fala o autor em seu ensaio sobre Nietzsche (Foucault, 1994-IV, p. 136-57). As questões, portanto, são diferentes. Menos do que se perguntar pelo "o que é?" numa busca que situa seu discurso num espaço radicalmente a-historicizante, Foucault coloca a pergunta "como se tornou?". É por isso que na sequência dessa definição ele precisará o que chama de modos de subjetivação e de objetivação: porque seu pensamento dedica-se a se perguntar sobre como, quais possibilidades, quem, porque nos tornamos isso que somos atualmente.

Nessa medida, seu modo de fazer filosofia está diretamente ligado à história, mas não é uma história estrita da filosofia: porque para perceber como esses "modos" são constitutivos de um saber possível, ele não se restringe aos "modos" da filosofia tradicional que se põe a pergunta sobre o que não pode responder, em busca de um saber impossível sobre a essência atemporal, a origem das coisas ou o fundamento universal da ética. "História crítica do pensamento" pode ser um dos sintagmas da filosofia na medida em que percebemos a filosofia como atividade de compreensão de nossas práticas, como um modo de saber o que nos tornamos, bem como tornamos certos objetos possíveis. Ela seria uma nova maneira de nutrir essa amizade pelo que ainda não sabemos, mas que, ao contrário de dirigir suas dúvidas na direção do infinito, se pergunta pelas coisas da vida presente, pelo modo de vida atual.

Assim ele escapa aos dilemas da questão ontologicamente normativa, a saber, de se perguntar "o que é?". Se aceitarmos que os impasses para responder a essa questão estão ligados a uma demanda por ser "a favor ou contra", a certos pressupostos ontológicos inconscientes, percebemos simultaneamente a historicidade da questão, ou seja, como cada época exclui ou aceita respostas específicas para a questão segundo pressupostos partilhados. Isso inevitavelmente salienta a normatividade implicada por esse tipo de suposição ontológica. A isso Foucault denominará atos de problematização. Embora só a tenha "isolado" suficientemente em seus últimos escritos, como admite, "as coisas mais gerais são as que aparecem em último lugar" (Foucault, 1994-IV, p. 670), ele 
deixa claro que problematização "é o conjunto das práticas discursivas e não-discursivas que faz alguma coisa entrar no jogo do verdadeiro e do falso e o constitui como objeto para o pensamento" (Foucault, 1994-IV, p. 671).

Um exemplo pode já ser observado retroativamente. Em $A s p a-$ lavras e as coisas, Foucault sugere uma história do mesmo, de como cada época dentro daquele recorte foi capaz de estabelecer para si mesmo um modo específico de colocar a questão "o que é?" e respondê-la segundo certas possibilidades, regulando e excluindo respostas. Ao fazer essa história do mesmo, ele não está sugerindo que o que se deu foi mesmo assim, mas que esse mesmo alterou-se com a passagem de um conjunto de saberes formados a partir da semelhança, para outros formados a partir da representação e da significação (FOUCAULT, 2007). O modo de problematizar se alterou. Assim, ele encontra uma maneira de narrar como nos tornamos o que somos, e não de responder definitivamente à questão sobre $o$ que somos.

Mas em quê tudo isso encerra o dilema de ser contra ou a favor de alguma coisa? Como essa história crítica do pensamento ajuda a se situar na luta? $\mathrm{Na}$ medida em que ela desafia o que existe, menos do que propõe alternati- vas; na medida em que situa seu trabalho "entre as pedras de espera e os pontos de suspensão" de modo a "abrir um canteiro, tentar e falhar, recomeçar outra vez" (Foucault, 1994-IV, p. 20). As metáforas arquitetônicas, constantes no trabalho de Foucault (Deleuze, 2006 , p. 280) remetem a um processo inacabado e contínuo: as pedras de espera são aquelas que, engastadas em outras peças ou pisos, permitem o acoplamento posterior de uma peça exterior (Albernaz \& Lima, 1998-I, p. 235); os pontos de suspensão lembram os balancins que sobem e descem as construções, os guindastes que elevam caçambas de concreto. Eis uma obra, a desse francês de Poitiers, que não termina porque abre canteiros, porque não se funda em profundidades imemoriais, porque não tem intenções panópticas, mas se dedica ao presente, a um solo temporal, sobre o qual caminhar, e questiona construções teóricas demasiado faraônicas.

Evidentemente, as metáforas arquitetônicas já são quase catacreses na história da filosofia: fala-se da busca por "fundamentos" com a mesma espontaneidade de um arquiteto que fala dos "dentes" de uma "coluna". Ao utilizá-las, Foucault nitidamente desvia-se de seu uso naturalizado ao se remeter para um conjunto de elementos errantes e passageiros, 
nada fundacionais, uma vez que tanto as esperas quanto os pontos de suspensão nos remetem aos céticos, para quem a busca de um fundamento não faz qualquer sentido. Em 1984, um entrevistador lhe pergunta se, na medida em que não afirma verdade universais, em que conduz o pensamento a paradoxos, bem como "faz da filosofia uma questão permanente", Foucault não seria um pensador cético, sua resposta foi a seguinte:

- Completamente [Absolument]. A única coisa que não aceitaria no programa cético é a tentativa que os céticos fizeram de chegar a um certo número de resultados em uma dada ordem - pois o ceticismo nunca foi um ceticismo total! Tentei levantar os problemas nos campos dados, e em seguida, fazer valer no interior de outros campos as noções efetivamente consideradas como válidas; em segundo lugar, me parece que, para os céticos, o ideal seria ser cético sabendo relativamente pouca coisa, mas as saber de maneira segura e imprescritível; enquanto que o que gostaria de fazer é um uso da filosofia que permita limitar os do- mínios do saber (Foucault, 1994-IV, p. 707).

Uma interpretação distorcida do que Foucault gostaria de fazer enquanto pensador cético pode ser desastrosa. Ele não é contra ou a favor dos domínios do saber não se trata de saber pouco seguramente, tudo a partir de uma dúvida radical, ou nada como finalidade ataráxica do cético. Seu objetivo claro de "limitar os domínios do saber" é cético na medida em que assinala que a aplicação e o uso desses saberes são válidas para a experiência, porém devem ser confrontadas com outras práticas que não se constituem como saberes - e o trabalho da filosofia parece ser o de assinalar as possibilidades emergentes quando nos deparamos com essas experiências-limite. Em outros termos, "limitar os domínios do saber" passa por "problematizar" as "experiências-limite" que funcionam como "pontos de suspensão" e "esperas" no jogo do verdadeiro e do falso.

Através dessa perspectiva estamos mais aptos a notar como sua maneira de fazer história ajuda a compreender que "imaginar um outro sistema atualmente ainda faz parte do sistema". Numa conversa em 1971, Foucault cita exemplos dessa problematização dos modos de vida: "a sociedade 
futura se esboça, talvez, através de experiências como a droga, o sexo, a vida comunitária, uma outra consciência, um outro tipo de individualidade... Se o socialismo científico se libera das utopias do século XIX, a socialização real liberar-se-á, talvez, no século XX, das experiências" (Foucault, 1994-II, p. 234). Menos do que ser a favor ou contra as drogas, o sexo liberal, a vida comunitária, Foucault assinala a importância dessas experiências como índices dos limites do saber, meios para a problematização dos modos pelos quais vivemos. Para compreender melhor a analogia feita nessa conversa pode ser instrutivo retornar ao Manifesto Comunista, cito-o:

A importância do socialismo e do comunismo crítico-utópicos está na razão inversa de seu desenvolvimento histórico. À medida em que a luta de classes se acentua e toma formas mais definidas, a fantástica oposição que lhe é feita perde qualquer valor prático e qualquer justificativa teórica. Por isso, se em muitos aspectos, os fundadores desses sistemas eram revolucionários, as seitas formadas por seus discípulos formam sempre sei- tas reacionárias. Aferramse às velhas concepções de seus mestres apesar do desenvolvimento histórico contínuo do proletariado. Procuram, portanto, e nisto são consequentes, atenuar a luta de classes e conciliar antagonismos. Continuam a sonhar com a realização experimental de suas utopias sociais: instituição de falanstérios isolados, criação de colônias no interior, fundação de uma pequena Icária edição em formato reduzido da nova Jerusalém e para dar realidade a todos esses castelos no ar veem-se obrigados a apelar para os bons sentimentos e os cofres dos filantropos burgueses. Pouco a pouco caem na categoria de socialistas reacionários ou conservadores descritos anteriormente, e só se distinguem deles por um pedantismo mais sistemático, uma fé supersticiosa e fanática nos efeitos miraculosos de sua ciência social (Marx \& Engels 2010: 67-8).

Esse trecho exprime sumariamente a relação dos autores do socialismo científico com as uto- 
pias do século XIX. Eles ressalvam com precisão os riscos que a adesão irrefletida a uma posição gera, nomeadamente quando ela é utópica, ou seja, quando quer defender e "dar realidade" a castelos no ar. Inspirando talvez as célebres comparações de Slavoj Žižek (2018) sobre como o uso do politicamente incorreto responde à exigência normativa do politicamente correto como duas faces de uma mesma moeda, Karl Marx e Friedrich Engels sugerem que os socialistas utópicos diferenciamse em muito pouco de socialistas reacionários e conservadores. $\mathrm{O}$ que os separa é somente um pedantismo baseado na ciência social, bastante semelhante àquele de quem busca raízes etimológicas ou históricas para justificar interditos politicamente corretos em torno de palavras já ressignificadas pelo uso. Ao criticar utopistas tais como Fourier, Cabet e Owen, Marx e Engels marcam uma posição que retoma as práticas reais das classes para alterar a realidade, ao invés de dar realidade a um objeto de uma imaginação singular. Eles não são contra ou a favor dos utopistas, mas mostram simultaneamente a importância e a posterior decadência dessa posição. Além disso, o recurso "aos bons sentimentos e aos cofres filantropos burgueses" destaca o quanto "imaginar ou- tro sistema atualmente faz parte do sistema". Sem esses bons sentimentos nutridos por burgueses, seria bastante improvável que a história do socialismo e do anarquismo pudesse assinalar o pionerismo utópico dos falanstérios e icárias.

Com esse exemplo pretendemos esclarecer melhor a ambiguidade presente no segundo elemento da comparação anteriormente elaborada por Foucault. Ao sugerir que uma sociedade futura se esboça a partir de certas práticas marginalizadas, ele assinala como se dá o processo através do qual imaginar outra existência se dá dentro dessa existência. A cultura hippie dos anos 1970 experimentou com propriedade essa possibilidade. Uma geração de jovens criados em famílias estruturadas e com condições variadas sonhou com um futuro de paz e de amor, em um mundo sem países e sem religiões, em que todos viveriam intensamente o agora. O que está culturalmente manifesto em filmes como Hair de Milos Forman ou em canções como "Imagine" de John Lennon soa semelhante aos experimentos dos utopistas ao menos em um aspecto: são sonhos geminados e resultantes dos limites colocados pelos próprios saberes vigentes de então. Diante de uma economia baseada na propriedade privada, que separa posses- 
sões pessoais da mesma maneira que países inteiros; em um mundo em que as divergências dão azo a guerras por territórios sagrados, por poços de petróleo ou mesmo por condições mínimas de vida; enfim, diante de tantos conflitos, imaginar outro sistema em que todos partilham o mesmo mundo é algo que não deve nos demover de pensar que esses sonhos são produtos derivados desses conflitos, como uma reação utópica, é verdade, mas uma reação, um vetor de força.

A socialização real de que fala Foucault, todavia não corresponde a essa utopia hippie. Sua sugestão é a de que da mesma maneira que o socialismo científico precisou criticar o socialismo utópico, compreendendo, todavia, sua originalidade; assim também num futuro próximo um conjunto de saberes compreenderá a originalidade contida nas experiências dessa geração, todavia criticandoa em aspectos considerados utópicos. A execução de projetos e pesquisas científicas através de financiamento coletivo, a profissionalização da prostituição em lugares como a Holanda ou a legalização de certas drogas pode ser vista como a socialização real resultante dessas "utopias" do século XX. Manifestações essas, diga-se de passagem, também sujeitas a críticas, bem como foi o caso do socialismo científico de Marx e Engels, pois é nesse jogo de reinvenção contínua entre atos de problematização incessantes, que não se para de imaginar outro sistema, ou outro problema atualmente naquele em que se vive.

$A$ atitude. Com isso em mente, podemos retomar a questão. Se não se trata de ser a favor ou contra, mas de problematizar, como supor que a Antiguidade é um erro? O enunciado surgiu em "O retorno da moral", última entrevista concedida por Foucault:

- Um estilo de existência é admirável. Você acha os gregos admiráveis?

- Não.

- Nem exemplares, nem admiráveis?

- Não.

- O que você acha deles?

- Não tão excelentes. Eles toparam imediatamente contra o que me parece ser o ponto de contradição da moral antiga: entre, de um lado, a busca obstinada por um certo estilo de existência e, de outro, o esforço por tornálo comum a todos, estilo que os aproximou sem dúvida mais ou menos obscuramente de Sêneca e de 
Epiteto, mas que só encontrou a possibilidade de se investir no interior de um estilo religioso. Toda a Antiguidade me parece ter sido um "erro profundo" (Foucault, 1994IV, p. 698).

Não seria difícil acusar Foucault de generalização apressada ao dizer que "toda a Antiguidade parece ter sido um 'erro profundo"'. Um comentador distraído poderia se desviar desse enunciado e apresentar as diversas análises do autor sobre a estética da existência, a parresía, o uso dos prazeres, o cuidado de si, sobre as tentações da carne, enfim, toda uma história crítica da sexualidade que encontrará na Antiguidade em sentido amplo do termo, dos gregos do século IV a.C. aos cristãos, um foco de atenção nos últimos anos de vida, como assinala Frédéric Gros, editor dos últimos cursos de Foucault (in Lawlor 2014, p. 556). Com isso, essa personagem se desviaria do problema e não faria mais do que parafrasear leituras sem exercer uma atitude crítica, tanto diante do que sugere Foucault, quanto da própria Antiguidade, sustentando assim uma adesão irrefletida aos temas de pesquisa levantados por Foucault. O próprio Frédéric Gros não se demite de salientar algo relevante, fornecendo uma pista sobre como compreender esse enunciado ao sugerir que "os antigos para Foucault perturbam nossas modernas certezas. E eles estavam aptos para tanto, para nos perturbar desse modo, não porque as verdades deles seriam mais verdadeiras do que as nossas, mas porque elas eram outras" (Idem, p. 559). Assim, menos do que adotar uma postura nostálgica, o comentário de Gros sugere que as problematizações da Antiguidade feitas por Foucault constituem uma alteridade relevante para a nossa atualidade, e não simplesmente um repositório de soluções a serem novamente traduzidas e catalogadas. Com isso em mente, tentaremos perceber melhor em que medida Foucault estaria se referindo à Antiguidade como um erro profundo, uma vez cientes de que ele retorna a ela despertando um encanto indisfarçável por parte de muitos leitores.

Mais adiante, ainda na mesma entrevista, ele continua: "Toda a experiência Grega pode ser revista um pouco da mesma maneira, tendo em conta, em cada caso, as diferenças de contexto e indicando a parte dessa experiência que pode talvez se salvar e aquela que, pelo contrário, se pode abandonar." (Foucault, 1994-IV, p. 702). A sugestão é a de que ao retornar aos antigos 
e problematizar certas experiências, tornamo-nos aptos a perceber o quanto somos diferentes e não tanto o quanto podemos ser semelhantes. Nesse sentido, partes da experiência da Antiguidade Grega podem ser abandonadas, e evidentemente, outras acabam por ser salvas. Essa sugestão ainda um tanto vaga não especifica qual seria esse erro profundo, mas permite supor que há algo de errado a ser abandonado.

No final da entrevista, no entanto, ao ser confrontado com a questão sobre se haveria ou não uma teoria do sujeito entre os gregos, Foucault esclarece que não acredita ser necessário reconstituir "uma experiência do sujeito" na Grécia. Isso porque a experiência, ou seja, a maneira de problematizar a si mesmos dos gregos não exigia uma "definição de sujeito". Ele sugere ainda que, baseado na literatura, se "nenhum pensador grego nunca encontrou uma definição de sujeito, nem nunca a buscou, diria simplesmente que não há um sujeito", isto é, não há uma teoria nesse sentido, porque não há problematização nesse sentido. Todavia, ele ressalva:

O que não quer dizer que os gregos não se esforcem por definir as condições pelas quais se daria uma experiência que não é aquela do sujeito, mas do indivíduo, na medida em que ele busca se constituir como mestre de si. Faltava à Antiguidade Clássica ter problematizado a constituição de si como sujeito; inversamente, a partir do cristianismo, houve o confisco da moral pela teoria do sujeito. Ora uma experiência moral essencialmente centrada sobre o sujeito não me parece mais satisfatória hoje. E por isso mesmo um certo número de questões se colocam a nós nos mesmos termos em que elas se colocaram na Antiguidade. (Foucault, 1994-IV, p. 706)

Do fato histórico de não haver uma noção de sujeito não se segue que não haja algum tipo de experiência de si na Grécia, ou em outros termos, se o sujeito não é problematizado pelos gregos, há, todavia, uma problematização sobre si mesmo presente na Antiguidade Clássica, como Foucault vai desenvolver no segundo volume de sua história da sexualidade, $O$ uso dos prazeres (1984). A estética da existência é vista por Foucault como um dos modos de sujeição pelos quais o indivíduo se encon- 
tra vinculado a um conjunto de regras e de valores, caracterizado neste caso pelo ideal de viver belamente, de ser mestre de si, e de deixar uma memória de uma existência bela (Foucault, 1994IV, p. 384; 397; CASTRO, 2009, p.151). Todavia, o que não há na problematização grega sobre como ser mestre de si é a subordinação dessa estética da existência a uma moral, o que será feito pelo cristianismo através de uma teoria do sujeito, ou seja, da subordinação, da sujeição do indivíduo a um conjunto de princípios morais. Com essa teoria do sujeito, o cristianismo proporá uma nova problematização que "confisca a moral", restringindo-a a possibilidades dadas por essa teoria. Já não se pensa mais em como criar para si uma existência boa e bela, numa estética da existência semelhante à dos gregos, mas a partir de uma teoria sobre como o indivíduo deve ou não se sujeitar.

Evidentemente, toda a crítica empreendida em direção à noção de sujeito não está sendo renegada por Foucault em nome de uma nova teoria do sujeito, e por isso "uma experiência moral" centrada sobre tal noção não parece satisfatória para a problematização da atualidade. Nos tempos em que "Deus morreu", num mundo desencantado não faz mais sentido insistir numa problema- tização centrada na noção de sujeito. Ela tornou-se uma posição estratégica dissolvida na prática da linguagem, não estando ela mais submetida necessariamente a uma experiência moral específica como a do cristianismo (Foucault, 2007). Como Foucault sugere na entrevista a Alessandro Fontana: "penso efetivamente que não há um sujeito soberano, fundador, uma forma universal de sujeito que se poderia reencontrar em todos os lados. Sou bastante cético e bem hostil para com essa concepção de sujeito" (Foucault, 1994-IV, p. 733). Não seria a primeira vez que esse ceticismo se manifestaria. A despeito dos deslocamentos teóricos oferecidos pelos textos em torno da Antiguidade, a problematização em torno desse sujeito soberano, emergente no cristianismo, é recorrente (FOUCAULT, 1944-IV, p. 223; 633-4; 657). Com isso em mente, podemos retomar o trecho supracitado de sua última entrevista:

A busca de estilos de existência tão diferentes uns dos outros quanto possíveis me parece um dos pontos pelos quais a busca contemporânea de uma forma de moral que seria aceitável para todo mundo - no sentido de 
que todo mundo deveria a ela se submeter - me parece catastrófica. Mas seria um contrassenso querer fundar uma moral moderna sobre a moral antiga passando por cima da moral cristã. Se eu empreendi um estudo tão longo, seria para tentar evidenciar como o que chamamos de moral cristã está incrustado na moral europeia, não só desde os primórdios do mundo cristão, mas desde a moral antiga (Foucault, 1994-IV, p. 706-7).

Esse comentário colabora para elucidar com mais clareza porque ele considera que Antiguidade seria um erro profundo, sem que com isso se incorra em algum tipo de avaliação anacrônica. Foucault salienta que a busca de uma moral para todos seria catastrófica em sua atualidade exatamente porque a problematização atualmente é outra. Uma vez que não há mais o problema do sujeito soberano, a questão deixa de ser aquela relativa à forma universal para a qual uma estética da existência ou uma teoria do sujeito moralizadora para todos se remeteriam.

Em todo caso, para que isso se tornasse claro, Foucault argumentou em sua História da Sexuali- dade $(1984,1985,2018)$ no sentido de mostrar como o sujeito não é um problema que desde sempre existiu para a moral europeia, ponto de emergência das morais ditas ocidentais. Ele emergiu em determinado momento, criando um problema que não existia para os gregos; surgiu a partir dos cristãos graças ao "confisco da moral" da Antiguidade; e que, provavelmente, com a busca por estilos de existência tão diferentes uns dos outros na atualidade, ele deixou de poder ser problematizável tal e qual. Segundo a sugestão de Beatrice Han, "o modelo grego desempenha o papel de uma matriz mais simples de avaliar a modernidade a contrario" (Han, 2012, p. 10). Em termos simplificadores: por um lado Foucault sugere que, para os gregos, há estética da existência sem uma teoria do sujeito, mas com um objetivo determinado - o de ser mestre de si, o de ter, segundo o estilo ideal, uma existência boa e bela; e por outro, para boa parte do cristianismo (Foucault ressalva algumas seitas ascéticas), essa experiência de busca de um estilo é confiscada pela moral, permitindo o surgimento de uma teoria do sujeito, o que anula a necessidade de se tornar mestre de si, uma vez que se está assujeitado. Cito-o:

Esta elaboração de sua 
própria vida como uma obra de arte pessoal, mesmo que ela obedeça a cânones coletivos, estava no centro, me parece, da experiência moral, da vontade de moral da Antiguidade; bem como, no Cristianismo, com a religião do texto, a ideia de uma vontade de Deus, e o princípio de obediência, a moral ganha muito mais a forma de um código de regras (somente algumas práticas ascéticas estiveram mais ligadas ao exercício de uma liberdade pessoal). Da Antiguidade ao cristianismo, passe-se de uma moral que era essencialmente uma busca de uma ética pessoal a uma moral como obediência a um sistema de regras. E se eu me interessei pela Antiguidade, é que, por toda uma série de razões, a ideia de uma moral como obediência a um código de regras está prestes, agora, a desaparecer, senão já desapareceu. E a essa ausência de moral, deve responder uma busca que é aquela de uma estética da existência (Foucault, 1994-IV, p. 731).
O "erro" aparece aqui de forma mais clara e menos vaga: apesar de terem sabido elaborar uma estética da existência, ou seja, apesar de terem sido capazes de conceber a própria existência, enquanto indivíduos, como uma obra de arte pessoal, os antigos o faziam tendo em vista cânones coletivos. É por isso que, por mais intrigante e estimulante que seja pensar na problemática de uma estética da existência a partir dos gregos, ela é completamente distinta da nossa experiência, porque ali se tratava de criar uma vida como obra a partir de uma estilística pré-concebida, ou se quisermos, de uma retórica do que seria a boa vida. A Antiguidade seria um erro para Foucault na medida em que então se acreditava ser possível imaginar um estilo que seria o bom e o belo, estabelecendo uma verdade do bem agir. Essa estilização engessada do bem viver dá lugar com o cristianismo a um código de regras fundado presumidamente na vontade de seu Deus e no princípio de obediência. Desaparece a experiência da estilização da existência a partir de modelos pré-concebidos para dar lugar à teoria do sujeito. Retornar a ambos não seria uma solução para pensar a modernidade, mas serve para compreender à nossa maneira de problema- 
tizar que, conforme a sugestão anterior de Foucault depende desses dois elementos, a saber, da retomada plural de uma estética da existência de um modo desconhecido até então $e$ de uma dissolução da teoria do sujeito soberano.

Se os gregos são uma matriz ao contrário isso se dá porque se invertermos o modo como eles problematizavam a própria existência encontramos algo semelhante a atitude moderna. Ao retirarmos daquela estética da existência sua finalidade, ou seja, a necessidade de fazer coincidir a vida como obra de arte com a vida boa e bela segundo um estilo pré-determinado, estaremos diante da atitude moderna que Foucault exemplifica através de certa leitura de Kant, como vemos em "O que são as Luzes?":

Ao me referir ao texto de Kant, me pergunto se não se pode considerar a modernidade como uma atitude mais do que como um período histórico. Por atitude, quero dizer um modo de relação que concerne à atualidade; uma escolha voluntária que se faz por alguns; enfim, uma maneira de pensar e de sentir, uma maneira também de agir e de se conduzir que, de uma só vez, marca uma pertinência e se apresenta como uma tarefa. Um pouco, sem dúvida, como o que os gregos chamam de éthos. Por conseguinte, mais do que querer distinguir o "período moderno" das épocas "pré" e "pós" modernas, creio que seria melhor investigar como a atitude da modernidade, desde que ela se forma, se encontra em luta com atitudes de "contramodernidade" (Foucault, 1994-IV, p. 568).

Nota-se aqui como esse "erro" profundo ajuda a pensar. Como sugere Deleuze, "Foucault diz: os gregos fizeram muito menos ou muito mais, como quiserem" (1988, p. 121), de modo que não se trata de reproduzir o éthos ou a atitude dos gregos. Se éthos é comumente traduzido por hábito ou costume, perde-se evidentemente a especificidade que essa palavra possui, e mesmo a disputa em torna de seu sentido. Barbara Cassin sugere em seu verbete "Morais" do Dicionário dos intraduziveis (2014, p. 691-3) que muitas das dificuldades e mesmo das confusões entre costumes e morais, entre morais e éticas, derivam de uma concepção de éthos. Ela assinala em sua sumária abordagem desse problema um interessante quiasma inicial presente entre os sentidos filosóficos do termo atribuídos por Platão e Aristóteles: "onde Platão conforta o naturalista com o argumento de que o hábito é inato, Aristóteles neutraliza o que é dado para nós como natural argumentando pela responsabilidade prática" (2014, p. 
693). Se por um lado haveria uma naturalização do éthos, por outro, ele seria da ordem do que é inventado, nutrido, criado. Aristóteles que teria inovado com o título de sua Ética (2014, p. 692) é particularmente importante para a compreensão do sentido de ética como ação ou ato, como sugere Cassin ao recolher passagens da Poética, da Retórica e da Ética Nicomaqueia. O que gostaríamos de salientar antes de retomar o nosso ponto é o elemento ativo destacado pela autora em sua leitura de Aristóteles. Ao contrário do que as traduções por hábito ou costume poderiam levar a supor, a saber, de que éthos é algo que passivamente se forma no indivíduo, Cassin sugere a ligação fundamental entre éthos e a prática ativa de uma virtude (2014, p. 692). Por fim, ela sugere "que a maioria dos filósofos que buscaram definir os termos [gregos ligados ao éthos] em suas próprias linguagens, como Cícero ou G.W.F. Hegel, tentaram encontrar um conjunto de problemáticas equivalentes para a Grécia, assim situando a tarefa da tradução no coração de sua reflexão" (2014, p. 693).

O primeiro elemento de contraste da sugestão de Foucault com uma tradição de interpretação do éthos surge indiciariamente aqui, porque a equivalência entre éthos e atitude é improvável apesar de possível. O autor, provavelmente ciente da disputa em volta do termo, sugere menos do que afirma. Ele diz, "um pouco, sem dúvida". "Um pouco" porque evidentemente a problematização grega não é equivalente à moderna, e por isso éthos e atitude seriam duas coisas distintas e intraduzíveis entre si. Sem dúvida guardam alguma coisa em comum, porque em ambos os casos algo da condução de si está em questão. Não à toa, atitude é definida aqui como uma maneira de governar a si mesmo, isto é, de agir, de se conduzir perante os outros, todavia ativa, uma vez resultante de uma escolha e imbuída de uma tarefa. A atitude da modernidade, definida no texto de Kant como aquela de sapere aude (KANT, 2012), ou seja, de emancipar-se numa atitude de maioridade, de ousadia e de coragem de buscar a verdade, será exemplificada por Foucault através da figura de Baudelaire em uma vontade de "heroicizar o presente". Heroicização irônica, uma vez que não se trata da sacralização de um momento ou da tentativa de perpetuá-lo, bem como não se trata de se recolher numa curiosidade fugidia, de uma atitude de flanêrie que se contenta em prestar atenção em coisas distraidamente e colecionar lembranças sem qualquer cri- 
tério. A essa atitude, Baudelaire opõe aquela do homem da modernidade. Cito um trecho de $O$ pintor da vida moderna:

Ele vai, corre, procura. Seguramente esse homem, esse solitário dotado de uma imaginação ativa, sempre viajando através do grande deserto de homens, tem uma tarefa mais elevada do que aquela de um puro flâneur, uma tarefa mais geral, diferente da do prazer fugidio da circunstância. Ele busca algo que nos permitirão chamar de modernidade. Trata-se para ele de destacar da moda o que ela pode conter de poético no histórico (Baudelaire apud Foucault, 1994-IV, p. 569-70).

Com essa retomada de Baudelaire, Foucault enceta uma maneira diferente de encarar a invenção de si mesmo, porque não se trata simplesmente de se relacionar com uma interioridade fugidia, mas de, através do enfrentamento dessa solidão, encontrar algo "poético no histórico". Se a Antiguidade é um erro profundo, assim seria na medida em que a tarefa de viver uma vida bela e boa não dependeria desse caráter continuamente investigativo e imaginativo, típico do homem moderno. Evidentemente, uma avaliação justa desse erro só seria possível sob a pecha de anacronismo. Mas o alerta passageiro e ocasional de Foucault não merece desprezo. Ele quer que evitemos assumir uma atitude de flanêrie em relação ao modo de problematizar grego que em muito é distinto do moderno. Somente a partir da modernidade, quando da emergência de fenômenos como a moda, quando se pôde tanto estilizar os corpos quanto submetê-los a certos padrões, faz sentido sugerir que a atitude emancipada é a de perceber o que "ela pode conter de poético no histórico", ou seja, o que em meio a tantos padrões surge como algo que desafia os nossos limites, perturba uma experiência que acumula estilos sem pensar na invenção de si mesmo.

A atitude de contramodernidade aparece como aquela que busca traduzir o éthos para solucionar um problema presente, que é a favor de uma tendência de cortes de roupa contra todas as outras, que acumula incessantes citações dos antigos, citando-as como sinal de sabedoria, num gesto tão automático quanto a subida ou descida de um elevador. $\mathrm{O}$ modo de viver dos antigos não só pode ter sido uma maneira de errar, como serve 
de exemplo de errância, de caminho já percorrido e sobre o qual só nos cabe perceber as pegadas, entender as marcas e investigar seus problemas. A atitude do filósofo é essa de ensaiar afinal, de esboçar algo de poético no histórico de tal modo que menos do que mais um quadro na parede, seus gestos sirvam como uma experiência modificadora de si e de seu entorno, de um jeito tal que ninguém na Antiguidade pôde experimentar.

\section{Referências}

ALBERNAZ, Maria Paula; Lima, Cecília Modesto. Dicionário ilustrado de arquitetura. São Paulo: Pró-Editores, 1997-1998 (2 vol.).

BUTLER, Judith. A vida psíquica do poder. Trad. Rogério Bettoni. Belo Horizonte: Autêntica, 2017.

CANDIOTTO, C. "A genealogia da ética de Michel Foucault". In: Educação e filosofia. V. 27, n 53. Uberlândia: 2013.

CASSIN, Barbara. Dictionary of untranslatables: a philosophical lexicon. New Jersey: Princeton, 2014.

CASTRO, Edgardo. Vocabulário de Foucault - um percurso pelos seus temas, conceitos e autores. Trad. Ingrid Müller Xavier. Belo Horizonte: Autêntica, 2009.

DELEUZE, Gilles. Foucault. Trad. Cláudia S. Martins. São Paulo: Brasiliense, 1988.

- Foucault and prison. In: Two Regimes of Madness: texts and interviews. Ed. David Lapoulaje; trans. Ames Hodges and Mike Taormina. New York: Semiotext(e), 2006.

FOUCAULT, Michel. Qu'est-ce que la critique? Bulletin de la Société Française de Philosophie. Paris : 1978.

. "Pour en finir avec les mensonges", Le Nouvel Observateur, 21 de junho de 1985. pp. 76-7.

- História da sexualidade II: o uso dos prazeres. Trad. Maria T. C. Albuquerque. Rio de Janeiro: Graal, 1984.

. História da sexualidade III: o cuidado de si. Trad. Maria T. C. Albuquerque. Rio de Janeiro: Graal, 1985.

. Dits et écrits (I-IV tommes). Paris: Gallimard, 1994.

As palavras e as coisas: uma arqueologia das ciências humanas. Trad. Salma T. Muchail. São Paulo: Martins Fontes, 2007. 9a Ed. 
- O governo de si e dos outros.Trad. Eduardo Brandão. São Paulo: Martins Fontes, 2010.

. Histoire de la sexualité IV: les aveux de la Chair. Paris : Gallimard, 2018.

GROS, Fréderic. "Situação do curso". In: O governo de si e dos outros.Trad. Eduardo Brandão. São Paulo: Martins Fontes, 2010.

GUTTING, Gary. Michel Foucault's Archaeology of Scientific Reason.Cambridge: Cambridge Uni., 1989.

HAN, Béatrice. Foucault's critical project: Between the Transcendental and the Historical. Stanford: Stanford Uni., 2012.

KANT, Immanuel. An answer to the question: "What is elightenment?". Trans. H. B. Nisbet. Londres: Penguin, 1970.

- "Resposta à Questão: O que é o Esclarescimento? [Beantwortung der Frage: Was ist Aufklärung?]". In: Cognitio. São Paulo, v. 13, n. 1, p. 145-154, jan./jun. 2012. Lawlor, Leonard; Nale, John. The Cambridge Foucault Lexicon. New York: Cambridge, 2014.

MARX, Karl; Engels, Friedrich. Manifesto Comunista (1848). Trad. Álvaro Pina, 1. ed. rev. São Paulo: Boitempo, 2010.

MONTAIGNE, Michel de. Ensaios. 3 vols. Trad. Rosemary Abílio. São Paulo: Martins Fontes, 2000.

NEHAMAS, A. The art of living: Socratic Reflections from Plato to Foucault. Berkeley: University of California Press, 1998.

SOARES, Jean. As ficções da filosofia de Michel Foucault. Tese de doutorado. Rio de Janeiro: PUC-Rio, 2018.

TROMBATORI, Ducio. "Introduction". In : Foucault, M. Remarks on Marx. Trans. James Goldstein \& James Cascaito. New York: Semiotext(e), 1991.

ŽIžEK, Slavoj. "Trump e o retorno do politicamente incorreto". Blog da Boitempo, São Paulo, fev. 2016. Disponível em Blog da Boitempo. Acesso em: 20 de fevereiro de 2016.

. "A lição da vitória de Corbyn". Blog da Boitempo, São Paulo, jun. 2017. Disponível em Blog da Boitempo. Acesso em: 17 de junho de 2017.

“O que Hegel nos ensina sobre como lidar com Trump?". Blog da Boitempo, São Paulo, jan. 2018. Disponível em Blog da Boitempo. Acesso em: 18 de janeiro de 2018. 
Recebido: 29/12/2018

Aprovado: 30/07/2019

Publicado: 17/11/2019 